\title{
Preoperative Risk Factors for Dissatisfaction After Total Hip Arthroplasty Among Patients With Osteonecrosis of the Femoral Head
}

\section{Genta Takemoto}

Nagoya University

Taisuke Seki

Nagoya University

Yusuke Osawa (D ysk0568@yahoo.co.jp )

Nagoya University

Yasuhiko takegami

Nagoya University

Taiki Kusano

Nagoya University

Shiro Imagama

Nagoya University

\section{Research Article}

Keywords: Osteoarthritis, Osteonecrosis of the femoral head, Quality of life, Total hip arthroplasty

Posted Date: November 25th, 2020

DOI: https://doi.org/10.21203/rs.3.rs-103521/v1

License: () (1) This work is licensed under a Creative Commons Attribution 4.0 International License.

Read Full License 


\section{Abstract}

Background: The objective of this study was to investigate the preoperative risk factors for dissatisfaction after total hip arthroplasty for osteonecrosis of the femoral head.

Methods: A total of 71 patients (91 hips) with osteonecrosis of the femoral head who underwent total hip arthroplasty surgery in our hospital were included. The degree of satisfaction was evaluated using a visual analogue scale one year after the total hip arthroplasty. The patients were divided into two groups: the satisfied group (S group; visual analogue scale score $>20 \mathrm{~mm}$ ) and the dissatisfied group (D group; visual analogue scale score $<20 \mathrm{~mm}$ ). The results of the preoperative quality-of-life self-assessments, including the Short Form-36 and Japanese Orthopaedic Association Hip Disease Evaluation Questionnaire, were compared between the satisfied and dissatisfied groups. Multivariate analysis was performed to examine the independent preoperative risk factors.

Results: There were 49 patients (64 hips) and 22 patients (27 hips) in the S and D groups, respectively. Patient age was significantly higher in the $\mathrm{D}$ group, and the movement and mental scores obtained with the Japanese Orthopaedic Association Hip Disease Evaluation Questionnaire and the Mental Component Summary scores of the Short Form-36 were significantly lower. However, there were no between-group differences in the pain score obtained with the Japanese Orthopaedic Association Hip Disease Evaluation Questionnaire and the Physical Component Summary and Role/Social Component Summary scores of the Short Form-36. Multivariate analysis showed that age and mental score obtained with the Japanese Orthopaedic Association Hip Disease Evaluation Questionnaire were independent risk factors.

Conclusions: Preoperative age and mental score obtained with the Japanese Orthopaedic Association Hip Disease Evaluation Questionnaire strongly affected satisfaction levels observed one year after total hip arthroplasty in patients with osteonecrosis of the femoral head.

\section{Background}

Osteonecrosis of the femoral head (ONFH) causes severe hip pain and restricts patients' quality of life (QOL) due to collapse of the femoral head [1,2]. Total hip arthroplasty (THA) is the most widely used surgical procedure for the treatment of ONFH. Several studies have reported that the implant survival rate is between 89 and $99 \%$ within ten years of surgery, and that the incidence of THA being performed for ONFH has been increasing [3,4]. Numerous studies have reported that THA for ONFH necessitates several reoperations and often leads to complications $[5,6]$. Therefore, it is difficult to identify the optimal timing of THA for patients with ONFH to improve their QOL.

Several studies have reported the clinical characteristics associated ONFH, including bilateral cases and prevalence in young active people, as well as underlying diseases that are often associated with steroid and alcohol use $[7,8]$. Therefore, patient satisfaction after THA could not be correctly evaluated due to the complicated patient backgrounds [5]. Similarly, a previous report demonstrated that postoperative patient satisfaction with THA was poorer in patients with ONFH than in those with osteoarthritis (OA); however, 
the relationship between ONFH and QOL after THA remains unknown [9]. It is important to examine the risk factors for postoperative QOL decline related to postoperative dissatisfaction when considering treatment options and the timing of surgery. The objective of this study was to elucidate the relationship between postoperative dissatisfaction with THA in ONFH and preoperative risk factors, such as disease association, patient characteristics, and their effects on QOL.

\section{Materials And Methods}

All participants gave their written informed consent. This study was approved by the institutional review board of The Nagoya University Ethics Committee and was performed according to the principles of the Declaration of Helsinki. Between January 2013 and December 2017, 75 patients ( 96 hips) underwent THA for non-traumatic ONFH in our institute. Among them, one patient (one hip) who required early reoperation due to frequent dislocation, one patient (one hip) for whom patient-reported outcomes could not be evaluated, and two patients (three hips) who died during the follow-up period were excluded (Fig. 1). A total of 71 patients (91 hips) were observed, including 31 women and 40 men with a median age of 47.5 years (interquartile range: $31.8-63.2$ years; range: $18-81$ years). The mean body mass index was $22.3 \mathrm{~kg} / \mathrm{m}^{2}$ (interquartile range: $18.5-26.1 \mathrm{~kg} / \mathrm{m}^{2}$; range, $15.4-31.3 \mathrm{~kg} / \mathrm{m}^{2}$ ). The cohort consisted of 20 and 51 patients with bilateral and unilateral THA, respectively; seven patients had a history of hip surgery. The diagnosis of ONFH was based on physical examination, medical history, and image findings as described by the Japanese Investigation Committee (JIC) of the Ministry of Health, Labour and Welfare [10]. The etiology of ONFH was steroid-induced in 68 hips and alcohol-associated in 19 hips, with idiopathic osteonecrosis identified in four hips. The locations of the necrotic lesions in the weight-bearing portion were categorized using the JIC classification [11]. In this study, 13 hips were in stage 3B (collapse of the femoral head of $>3 \mathrm{~mm}$ ) and 78 hips were in stage 4 (osteoarthritic change).

THA was performed with the patients in a lateral position using the standard posterior approach; the same method was used on all patients. The distribution of implant types in the ONFH group was as follows: Super Secur-Fit stem, 58 hips; Accolade囚, 21 hips; Exceter, 12 hips; and Trident HA, 91 hips. For postoperative rehabilitation, walking and weight bearing exercises were performed in all cases.

Patient satisfaction with the THA was evaluated using the visual analogue scale (VAS), with anchors at 0 $\mathrm{mm}$ (best) to $100 \mathrm{~mm}$ (worst) one year after surgery. Patients with a VAS score $<20 \mathrm{~mm}$ were classified in the postoperative satisfaction group (S group) and those with a VAS score $>20 \mathrm{~mm}$ were classified in the postoperative dissatisfaction group ( $\mathrm{D}$ group); and preoperative patient background, diseaseassociated factors, and QOL were compared between the two groups [12]. Patients who underwent bilateral surgery on a different day were evaluated one year after the second operation. QOL questionnaires were used to evaluate all existing physical, mental, and social factors. Simultaneous evaluation of disease-specific and comprehensive assessment results has been recommended, with the Japanese Orthopaedic Association Hip Disease Evaluation Questionnaire (JHEQ) employed as the disease-specific assessment and Short Form-36 (SF-36) as the comprehensive assessment tools; these assessments were performed both preoperatively and one year after surgery [13-15]. The JHEQ was 
designed by the Japanese Orthopaedic Association taking into account Asian lifestyle behaviors, and consists of three components: pain, movement, and mental health. Each of the 21 subcomponents were scored between 0 and 28 points, with higher scores indicating better QOL. Scores for the Physical Component Summary (PCS), Mental Component Summary (MCS), and Role/Social Component Summary (RCS) sections of the SF-36 were also evaluated. The national standard is 50 points, with higher scores indicating a higher than average QOL.

For statistical analyses, between-group differences were evaluated using the Student's t-test and Chisquared test as appropriate according to the data distribution; $p$-values $<0.05$ were considered statistically significant. If a variable had a p-value $<0.05$ in the univariate analysis, it was used in the multivariate logistic regression analysis; all variables with a $p$-value $<0.05$ were considered statistically significant. The crude and adjusted odds ratios (ORs), and 95\% confidence intervals (Cls) were obtained. All statistical analyses were performed using SPSS (version 21, IBM Corp., Armonk, NY, USA).

\section{Results}

There were 49 patients (64 hips) in the S group and 22 patients ( 27 hips) in the D group. Patient age was significantly higher in the $D$ group $(57.4 \pm 15.9$ years vs. $45.4 \pm 16.5$ years: $p<0.05)$ than in the $S$ group. There were no significant differences between the two groups in terms of body mass index, diseaseassociated factors, JIC classification, and previous hip surgery (Table 1).

The JHEQ scores for assessing movement and mental components prior to surgery were significantly lower in the $D$ group $(4.2 \pm 4.2$ and $7.7 \pm 4.8$, respectively) than the $S$ group (12.4 \pm 7.8 and $36.7 \pm 18.6$, respectively; $p<0.01)$; however, the JHEQ scores for pain showed no significant differences between the groups. The RCS scores obtained from the SF-36 were significantly lower in the D group $(27.3 \pm 18.5)$ than in the $S$ group $(36.7 \pm 18.6: p<0.05)$. No significant differences in terms of the PCS and MCS components of the SF-36 were observed between the two groups (Table 2).

After surgery, the JHEQ scores for the movement, pain, and mental components were significantly lower in the $D$ group $(9.1 \pm 9.5,16.0 \pm 8.1$, and $11.7 \pm 5.7$, respectively) than the $S$ group $(17.7 \pm 5.7,24.7 \pm 4.3$, and $21.1 \pm 5.7$, respectively; $p<0.01)$. While the PCS and RCS scores of the SF-36 were significantly lower in the $D$ group $(29.3 \pm 15.4$ and $33.9 \pm 11.9$, respectively) than in the $S$ group $(39.2 \pm 12.8$ and $48.3 \pm 11.9$, respectively: $p<0.01$ ), there was no significant difference observed between the two groups in terms of the MCS component of the SF-36 (Table 3).

Age, the movement and mental scores obtained from the JHEQ, and the RCS scores of the SF-36 were selected as indicators of the patient's preoperative QOL. A multivariate logistic regression analysis was performed and as a result, age ([OR]: 1.04; 95\% [Cl]: 1.00-1.07; $\mathrm{p}<0.05)$ and JHEQ mental component scores (OR: $0.91 ; 95 \%$ [Cl]: 0.84-0.99; $p<0.05$ ) were found to be independent risk factors associated with postoperative dissatisfaction (Table 4). 


\section{Discussion}

Various factors have been reported in connection with poor preoperative predictive factors after THA, with old age and poor preoperative functional activity considered typical risk factors [16]. After THA, preoperative physical function is often decreased in the elderly, and improvement in functional activity can be difficult to achieve, especially when compared to the improvements seen in young patients [17]. In the current study, older age was considered an independent risk factor for postoperative dissatisfaction in patients with ONFH. In recent years, the use of surgical treatment for elderly patients with ONFH has increased, a result of the incidence of ONFH increasing with the age of the population [18]. Further, the activities of daily living often decrease rapidly with ONFH compared to OA due to collapse of the femoral head $[1,2]$. Thus, considering the evolution of the surgical technique, it is recommended that the elderly consider THA treatment as early as possible.

It is well known that functional activity is significantly impaired in patients with ONFH due to the collapse of the femoral head [19]. Previous reports have demonstrated that both mental state and hip-joint function are similarly impaired in patients with ONFH with progressing collapse of the femoral head $[1,2]$. Chen et al. reported a significantly higher prevalence of depression in patients with ONFH than in those with OA [20], and in another study, patients with ONFH had significantly lower mental scores after THA than patients with $O A[9]$.

The current study demonstrates that poor preoperative mental status was an independent risk factor for postoperative dissatisfaction with THA in patients with ONFH. In general, postoperative scores of patients with poor preoperative mental scores remained unchanged after THA surgery [21]. Therefore, preoperative depression should be carefully considered when performing THA in patients with ONFH. Additional studies have reported that patients with bilateral ONFH display significantly worse preoperative mental scores than those with unilateral ONFH $[2,22]$. Since many cases of ONFH occur bilaterally, incredibly careful judgment is considered necessary for these patients.

There were some limitations in the present study. Firstly, the number of patients in the dissatisfaction group ( $\mathrm{n}=22$ ) was considerably small; a greater number of patients would have increased the statistical power. Additionally, osteotomies were actively performed aimed toward joint preservation in young people; there was thus the possibility of patient selection bias when compared to centers that do not perform osteotomies. Secondly, the postoperative follow-up period was short, although Matsunaga et al. reported that there was no difference in QOL assessment findings after THA between one year and three years after surgery [20]. While long-term evaluation is desirable, the results of this study are considered important. Thirdly, ONFH-associated disease activity was not evaluated, and primary disease activity of ONFH may affect postoperative satisfaction after THA [23].

Considering recently reported long-term outcomes [9,24], We believe that THA should be the first choice for treatment of ONFH. However, THA is not recommended for young people due to the risk for multiple revision surgeries in the future; surgical strategies should be carefully selected since performing the appropriate joint-preserving surgery can provide long-term functional outcomes that are equivalent to 
those provided by THA [25]. Additionally, preoperative mental health greatly affects satisfaction after THA; understanding the details of the cause is thus considered necessary to carefully plan the timing and appropriate surgical procedure for improved patient satisfaction.

In conclusion, poor preoperative mental status and old age were found to be independent risk factors for postoperative dissatisfaction with THA in patients with ONFH.

\section{List Of Abbreviations}

D group, postoperative dissatisfaction group

JHEQ, Japanese Orthopaedic Association Hip Disease Evaluation

JIC, Japanese Investigation Committee of the Ministry of Health, Labour and Welfare

OA, osteoarthritis

ONFH, Osteonecrosis of the femoral head

MCS, Mental Component Summary of the SF-36

PCS, Physical Component Summary of SF-36

QOL, quality of life

RCS, Role/Social Component Summary of SF-36

S group, postoperative satisfaction group

SF-36, Short Form-36

THA, Total hip arthroplasty

VAS, visual analogue scale

\section{Declarations}

Ethics approval and consent to participate. This study was approved by the institutional review board of The Nagoya University Ethics Committee. Written consent to publish was obtained from the patients themselves.

Consent for publication. Written informed consent was obtained from the patient for the publication of this case report.

Competing interests. The authors declare that they have no competing interests. 
Funding. No funding

\section{Authors' contributions}

G. T: Study designed, Data collection, Data analysis, Image assessment, Statistical analysis, Writing the Paper.

T. S: Performed surgeries, Proofreading of the final paper.

Y. O: Data collection, Image assessment.

Y. T: Data collection.

T. K: Data collection.

S. I: Study designed, Proofreading of the final paper.

Acknowledgements. Not applicable

\section{References}

1. Hauzeur JP, Malaise M, de Maertelaer V. A prospective cohort study of the clinical presentation of non-traumatic osteonecrosis of the femoral head: spine and knee symptoms as clinical presentation of hip osteonecrosis. Int Orthop. 2016 Jul;40(7):1347-51.

2. Osawa Y, Seki T, Takegami Y, Kasai T, Higuchi Y, Ishiguro N. Do femoral head collapse and contralateral condition affect patient-reported quality of life and referral pain in patients with osteonecrosis of the femoral head? Int Orthop. 2018 Jul;42(7):1463-1468.

3. Kim YH, Choi Y, Kim JS. Cementless total hip arthroplasty with ceramic-on-ceramic bearing in patients younger than 45 years with femoral-head osteonecrosis. Int Orthop. 2010 Dec;34(8):1123-7.

4. Bedard NA, Callaghan JJ, Liu SS, Greiner JJ, Klaassen AL, Johnston RC. Cementless THA for the treatment of osteonecrosis at 10-year follow-up: have we improved compared to cemented THA? J Arthroplasty. 2013 Aug;28(7):1192-9.

5. Saito S, Saito M, Nishina T, Ohzono K, Ono K. Long-term results of total hip arthroplasty for osteonecrosis of the femoral head. A comparison with osteoarthritis. Clin Orthop Relat Res. 1989 Jul; (244):198-207.

6. Ancelin D, Reina N, Cavaignac E, Delclaux S, Chiron P. Total hip arthroplasty survival in femoral head avascular necrosis versus primary hip osteoarthritis: case-control study with a mean 10-year followup after anatomical cementless metal-on-metal 28- $\mathrm{mm}$ replacement. Orthop Traumatol Surg Res. 2016 Dec;102(8):1029-1034.

7. Hernigou P, Bachir D, Galacteros $F$. The natural history of symptomatic osteonecrosis in adults with sickle-cell disease. J Bone Joint Surg Am. 2003 Mar;85(3):500-4. 
8. Fukushima W, Fujioka M, Kubo T, Tamakoshi A, Nagai M, Hirota Y. Nationwide epidemiologic survey of idiopathic osteonecrosis of the femoral head. Clin Orthop Relat Res. 2010 Oct;468(10):2715-24.

9. Osawa Y, Taisuke Seki, Yasuhiko Takegami, Taiki Kusano, Kazuya Makida, Naoki Ishiguro.

Cementless total hip arthroplasty for osteonecrosis and osteoarthritis produce similar results at ten years follow-up when matched for age and gender. Int Orthop. 2018 Jul;42(7):1683-1688.

10. Sugano N, Kubo T, Takaoka K, Ohzono K, Hotokebuchi T, Matsumoto T, Igarashi H, Ninomiya S. Diagnostic criteria for non-traumatic osteonecrosis ofthe femoral head. A multicentre study. J Bone Joint Surg Br. 1999 Jul;81(4):590-5.

11. Sugano N, Atsumi T, Ohzono K, Kubo T, Hotokebuchi T, Takaoka K. The 2001 revised criteria for diagnosis, classification, and staging of idiopathic osteonecrosis of the femoral head. J Orthop Sci. 2002;7(5):601-5.

12. B. G. Brokelman, C. J. M. van Loon, W. J. Rijnberg. Patient versus surgeon satisfaction after total hip arthroplasty. J Bone Joint Surg Br. 2003 May;85(4):495-8.

13. Matsumoto T, Kaneuji A, Hiejima Y, Sugiyama H, Akiyama $H$, Atsumi T, Ishii M, Izumi K, Ichiseki T, Ito H, Okawa T, Ohzono K, Otsuka H, Kishida S, Kobayashi S, Sawaguchi T, Sugano N, Nakajima I, Nakamura S, Hasegawa Y, Fukuda K, Fujii G, Mawatari T, Mori S, Yasunaga Y, Yamaguchi M. Japanese Orthopaedic Association Hip Disease Evaluation Questionnaire (JHEQ): a patient-based evaluation tool for hip-joint disease. Subcommittee on Hip Disease Evaluation of the Clinical Outcome Committee of the Japanese Orthopaedic. J Orthop Sci. 2012 Jan;17(1):25-38.

14. OstendorfM, van Stel HF, Buskens E, Schrijvers AJ, Marting LN, Verbout AJ, Dhert WJ. Patientreported outcome in total hip replacement. A comparison of five instruments of health status. $J$ Bone Joint Surg Br. 2004 Aug;86(6):801-8.

15. Fukuhara S, Bito S, Green J, Hsiao A, Kurokawa K. Translation, adaptation, and validation of the SF36 Health Survey for use in Japan. J Clin Epidemiol. 1998 Nov;51(11):1037-44.

16. L D Buirs, L W A H Van Beers, V A B Scholtes, T Pastoors, S Sprague, R W Poolman. Predictors of physical functioning after total hip arthroplasty: a systematic review. BMJ Open. 2016 Sep 6;6(9): e010725.

17. Matsunaga-Myoji Y, Fujita K, Makimoto K, Tabuchi Y, Mawatari M. Three-Year Follow-Up Study of Physical Activity, Physical Function, and Health-Related Quality of Life After Total Hip Arthroplasty. J Arthroplasty. 2020 Jan;35(1):198-203.

18. Kaneko S, Takegami Y, Seki T, Fukushima W, Sakai T, Ando W, Ishiguro N, Sugano N. Surgery trends for osteonecrosis of the femoral head: a fifteen-year multi-centre study in Japan. Int Orthop. 2020 Apr;44(4):761-769.

19. Seki T, Hasegawa Y, Masui T, Yamaguchi J, Kanoh T, Ishiguro N, KawaBe K. Quality of life following femoral osteotomy and total hip arthroplasty for nontraumatic osteonecrosis of the femoral head. $J$ Orthop Sci. 2008 Mar;13(2):116-21.

20. Sheng-Bao Chen, Hai Hu, You-Shui Gao, Hai-Yan He, Dong-Xu Jin, Chang-Qing Zhang. Prevalence of Clinical Anxiety, Clinical Depression and Associated Risk Factors in Chinese Young and Middle-Aged 
Patients with Osteonecrosis of the Femoral Head. PLoS One. 2015 Mar 19;10(3): e0120234.

21. Nelson F. SooHoo, Zhongmin Li, Kate E. Chenok, Kevin J. Bozic. Responsiveness of Patient Reported Outcome Measures in Total Joint Arthroplasty Patients. J Arthroplasty. 2015 Feb;30(2):176-91.

22. Uesugi Y, Sakai T, Seki T, Hayashi S, Nakamura J, Inaba Y, Takahashi D, Sasaki K, Motomura G, Mashima N1, Kabata T, Sudo A, Jinno T, Ando W, Nagoya S, Yamamoto K, Nakasone S, Ito H, Yamamoto T, Sugano N. Quality of life of patients with osteonecrosis of the femoral head: a multicentre study. Int Orthop. 2018 Jul;42(7):1517-1525.

23. Wael A. Rahman, MD; Donald S. Garbuz, MD, MHSc; Bassam A. Masri, MD. Total hip arthroplasty in steroid-induced osteonecrosis: early functional and radiological outcomes. Can J Surg. 2013 Feb;56(1):41-6.

24. Ortiguera CJ, Pulliam IT, Cabanela ME. Total hip arthroplasty for osteonecrosis: matched-pair analysis of 188 hips with long-term follow-up. J Arthroplasty. 1999 Jan;14(1):21-8.

25. Osawa Y, Seki T, Okura T, Takegami Y, Naoki I, Hasegawa Y. Curved varus osteotomy versus total hip arthroplasty for osteonecrosis of the femoral head in patients under 50 years old. J Arthroplasty. 2020 Jan 18. pii: S0883-5403(20)30044-9.

\section{Tables}

Table 1. Patient demographic data. 


\begin{tabular}{|c|c|c|c|}
\hline Parameters & $\begin{array}{l}\text { Dissatisfaction Group } \\
n=22\end{array}$ & $\begin{array}{l}\text { Satisfaction Group } \\
\mathrm{n}=49\end{array}$ & $P$ values \\
\hline Sex, patients (Male/Female) & $15 / 7$ & $25 / 24$ & 0.178 \\
\hline Age (SD), years & $57.4 \pm 15.9$ & $45.4 \pm 16.5$ & $<0.01$ \\
\hline BMI (SD), $\mathrm{kg} / \mathrm{m}^{2}$ & $21.8 \pm 3.0$ & $22.3 \pm 3.6$ & 0.691 \\
\hline Aetiology hips, (St/AL/ION) & $18 / 7 / 2$ & $50 / 12 / 2$ & 0.801 \\
\hline Unilateral/Bilateral & $17 / 5$ & $34 / 15$ & 0.641 \\
\hline Stage, hips (3B/4) & $4 / 23$ & $9 / 55$ & 0.870 \\
\hline Previous hip surgery, hips (\%) & $2(9 \%)$ & $5(10 \%)$ & 1.000 \\
\hline Femoral stem, hips & & & 0.749 \\
\hline Super Securefit ${ }^{\mathrm{TM}}$ & 15 & 43 & \\
\hline Accolade $\rrbracket^{\mathrm{TM}}$ & 7 & 14 & \\
\hline Exeter $^{\mathrm{TM}}$ & 5 & 7 & \\
\hline \multicolumn{4}{|l|}{ Accetabular component, hips } \\
\hline TriAD HA ${ }^{T M}$ & 27 & 64 & 1.000 \\
\hline \multicolumn{4}{|c|}{ BMI, body mass index; St, Steroid; AL, Alcohol; ION, idiopathic ONFH; OA, osteoarthritis; } \\
\hline
\end{tabular}

Table 2. Clinical results before surgery. 


\begin{tabular}{|clll|}
\hline Parameters & $\begin{array}{l}\text { Dissatisfaction Group } \\
\mathrm{n}=22\end{array}$ & $\begin{array}{l}\text { Satisfaction Group } \\
\mathrm{n}=49\end{array}$ & Pvalues \\
\hline JHEQ & & & \\
\hline Movement (SD) & $7.4 \pm 6.6$ & $7.8 \pm 7.3$ & 0.852 \\
\hline Pain (SD) & $4.2 \pm 4.2$ & $8.2 \pm 7.8$ & $<0.01$ \\
\hline Mental (SD) & $7.7 \pm 4.8$ & $12.4 \pm 7.8$ & $<0.01$ \\
\hline SF-36 & $20.8 \pm 12.1$ & & 0.552 \\
\hline PCS (SD) & $48.4 \pm 11.7$ & $18.1 \pm 13.8$ & 0.214 \\
\hline MCS (SD) & $27.3 \pm 18.6$ & $33.9 \pm 12.1$ & 0.039 \\
\hline RCS (SD) & $36.7 \pm 18.6$ & \\
\hline $\begin{array}{l}\text { JHEQ Japanese Orthopedic Association Hip- Disease Evaluation Questionnaire, SF36 Short Form-36, } \\
\text { PCS Physical Component Summary, MSC Mental Component Summary, RCS Role/Social Component } \\
\text { Summary }\end{array}$ & & \\
\hline
\end{tabular}

Table 3. Postoperative clinical results.

\begin{tabular}{|c|c|c|c|}
\hline Parameters & $\begin{array}{l}\text { Dissatisfaction Group } \\
\mathrm{n}=22\end{array}$ & $\begin{array}{l}\text { Satisfaction Group } \\
\mathrm{n}=49\end{array}$ & $P$ values \\
\hline \multicolumn{4}{|l|}{ JHEQ } \\
\hline Movement (SD) & $9.1 \pm 9.5$ & $17.7 \pm 5.7$ & $<0.01$ \\
\hline Pain (SD) & $16.0 \pm 8.1$ & $24.7 \pm 4.3$ & $<0.01$ \\
\hline Mental (SD) & $11.7 \pm 5.7$ & $21.1 \pm 5.7$ & $<0.01$ \\
\hline \multicolumn{4}{|l|}{ SF-36 } \\
\hline PCS (SD) & $29.3 \pm 15.4$ & $39.2 \pm 12.8$ & $<0.01$ \\
\hline MCS (SD) & $50.2 \pm 11.7$ & $54.9 \pm 9.2$ & 0.08 \\
\hline RCS (SD) & $33.9 \pm 11.9$ & $48.3 \pm 11.9$ & $<0.01$ \\
\hline \multicolumn{4}{|c|}{$\begin{array}{l}\text { JHEQ Japanese Orthopedic Association Hip- Disease Evaluation Questionnaire, SF36 Short Form-36, } \\
\text { PCS Physical Component Summary, MSC Mental Component Summary, RCS Role/Social Componen } \\
\text { Summary }\end{array}$} \\
\hline
\end{tabular}

Table 4. Results of multivariate analyses for risk factors for postoperative dissatisfaction. 


\begin{tabular}{|llll|}
\hline Parameters & Odds Ratio & $95 \% \mathrm{Cl}$ & $P$ values \\
\hline Age & 1.04 & $1.00-1.07$ & 0.047 \\
\hline JHEQ & & 0.422 \\
\hline Pain & 0.96 & $0.87-1.06$ & 0.032 \\
\hline Mental & 0.91 & $0.84-0.99$ & 0.780 \\
\hline SF-36 & 0.99 & $0.94-1.05$ & \\
\hline \multicolumn{2}{|c|}{ MCS } & & \\
\hline $\begin{array}{l}\text { JHEQ Japanese Orthopedic Association Hip- Disease Evaluation Questionnaire, SF36 Short Form-36, } \\
\text { MSC Mental Component Summary, Cl Confidence interval }\end{array}$ & \\
\hline
\end{tabular}

\section{Figures}


April 2013 - March 2017

All THA cases for ONFH

(75 patients, 96 hips)

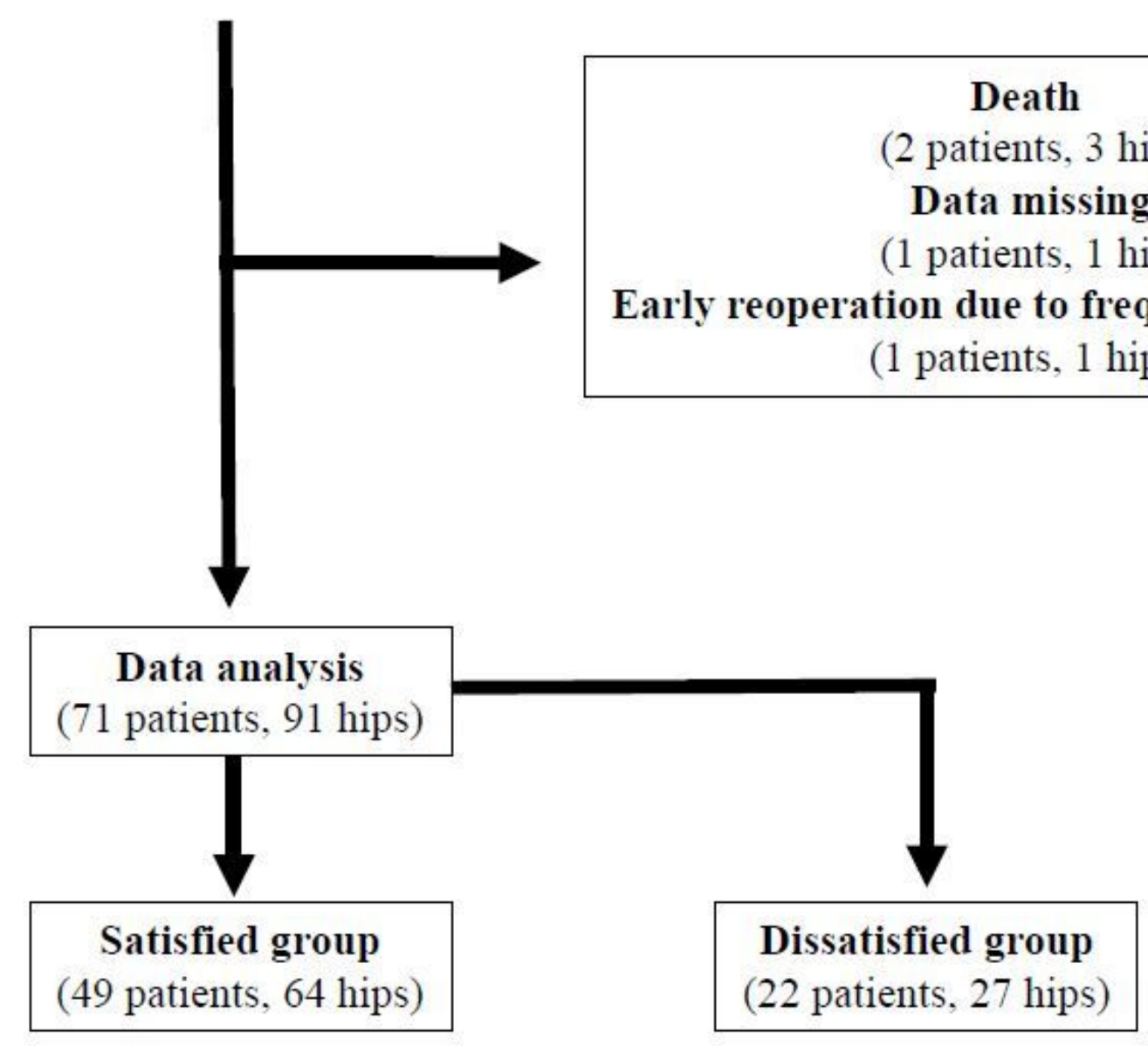

Figure 1

Enrollment flowchart. THA, total hip arthroplasty; ONFH, osteonecrosis of the femoral head. 
April 2013 - March 2017

All THA cases for ONFH

(75 patients, 96 hips)

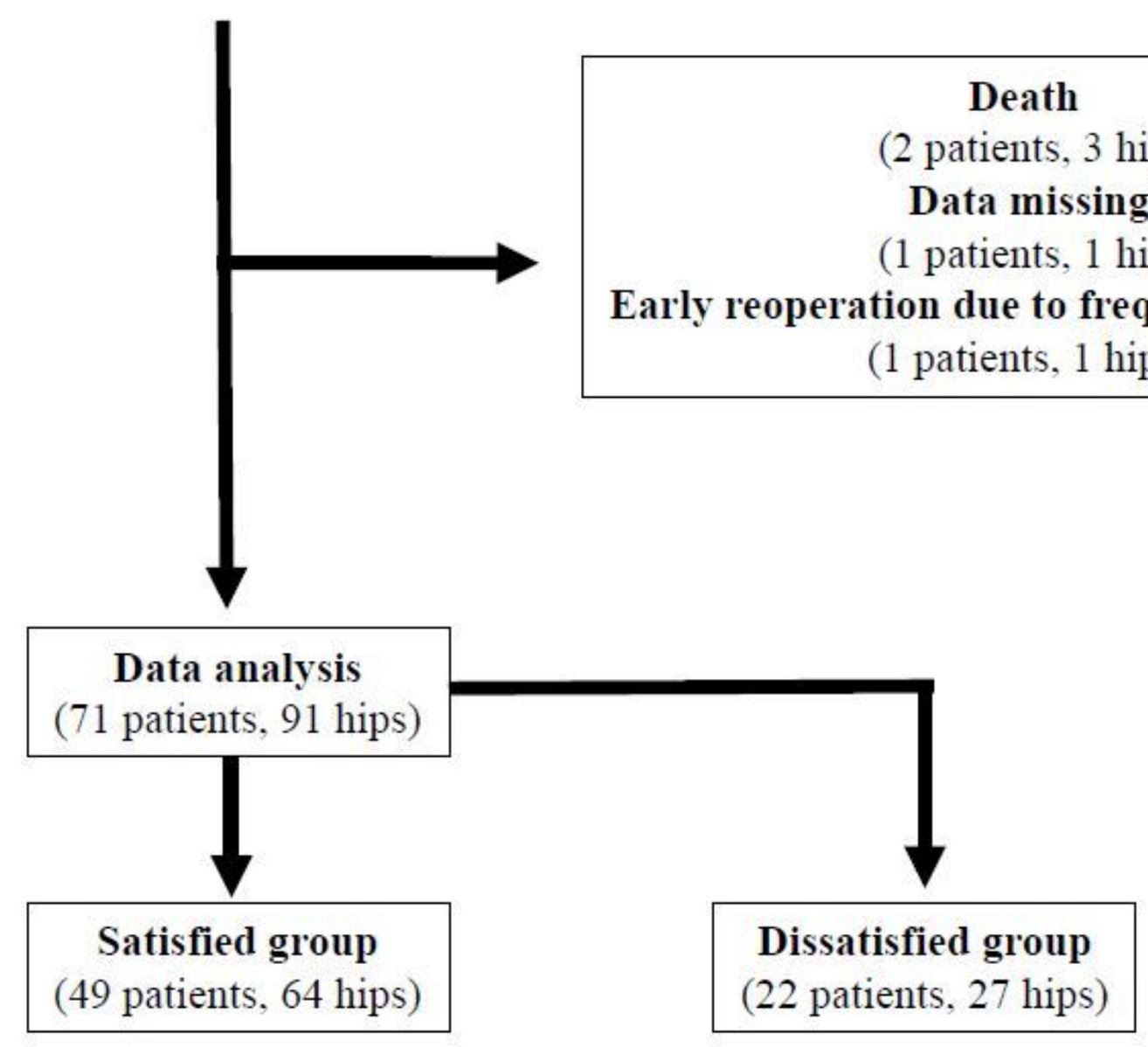

Figure 1

Enrollment flowchart. THA, total hip arthroplasty; ONFH, osteonecrosis of the femoral head. 